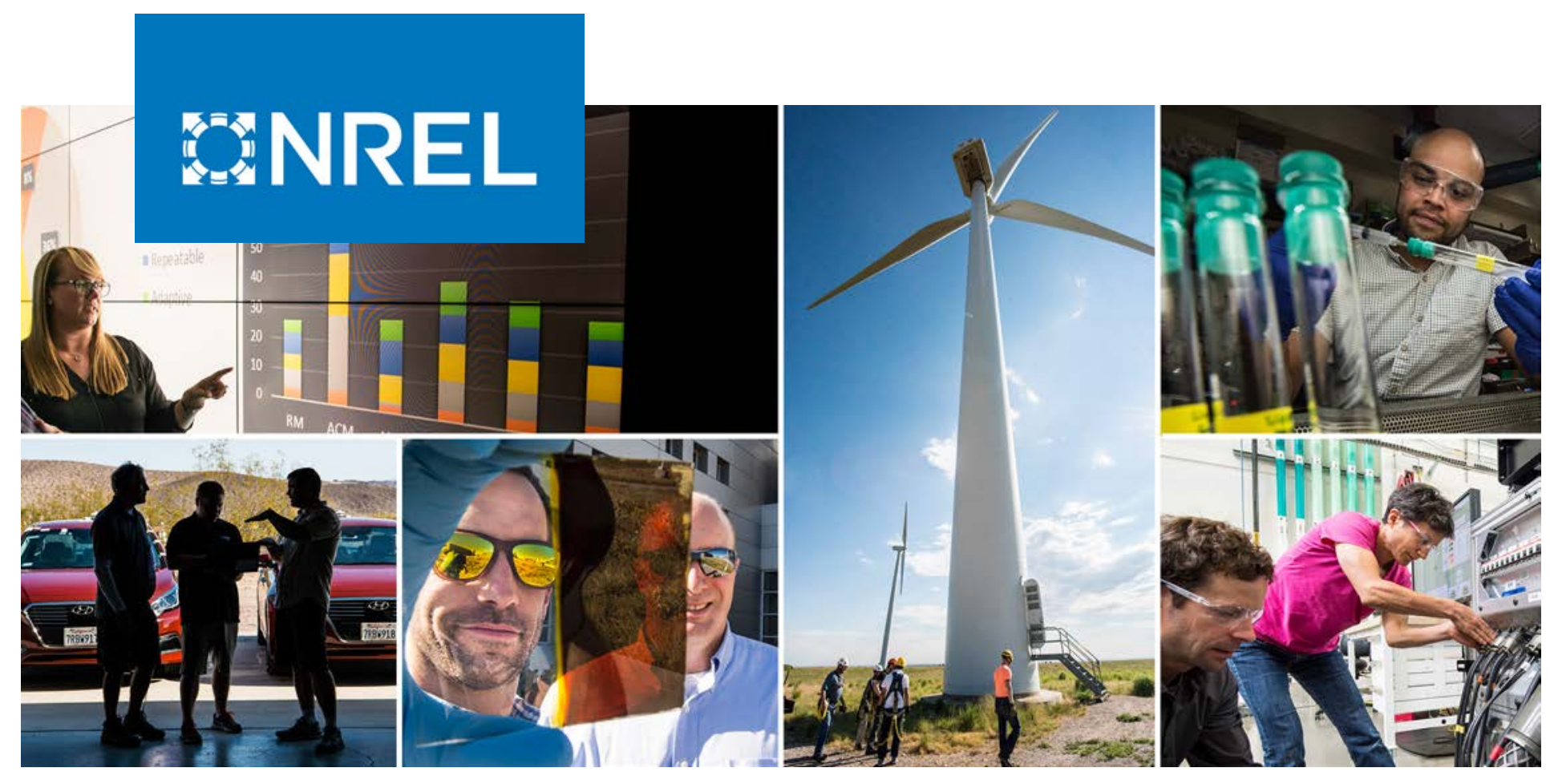

\title{
Surface Temperature Effect on Convective Heat Transfer Coefficients for Jet Impingement Cooling of Electric Machines with Automatic Transmission Fluid
}

\section{Preprint}

Bidzina Kekelia, Kevin Bennion, Xuhui Feng, Gilberto Moreno, J. Emily Cousineau, Sreekant Narumanchi, and Jeff Tomerlin National Renewable Energy Laboratory

Presented at ASME 2019 International Technical Conference and Exhibition on Packaging and Integration of Electronic and Photonic Microsystems (IPACK2019) Anaheim, California

October 7-9, 2019

NREL is a national laboratory of the U.S. Department of Energy Office of Energy Efficiency \& Renewable Energy

Operated by the Alliance for Sustainable Energy, LLC

This report is available at no cost from the National Renewable Energy Laboratory (NREL) at www.nrel.gov/publications.
Conference Paper NREL/CP-5400-74284

December 2019 


\section{WNREL}

\section{Surface Temperature Effect on Convective Heat Transfer Coefficients for Jet Impingement Cooling of Electric Machines with Automatic Transmission Fluid}

\section{Preprint}

Bidzina Kekelia, Kevin Bennion, Xuhui Feng, Gilberto Moreno, J. Emily Cousineau, Sreekant Narumanchi, and Jeff Tomerlin National Renewable Energy Laboratory

\section{Suggested Citation}

Kekelia, Bidzina, Kevin Bennion, Xuhui Feng, Gilberto Moreno, J. Emily Cousineau, Sreekant Narumanchi, and Jeff Tomerlin. 2019. Surface Temperature Effect on Convective Heat Transfer Coefficients for Jet Impingement Cooling of Electric Machines with Automatic Transmission Fluid: Preprint. Golden, CO: National Renewable Energy Laboratory. NREL/CP-5400-74284. https://www.nrel.gov/docs/fy20osti/74284.pdf.

NREL is a national laboratory of the U.S. Department of Energy Office of Energy Efficiency \& Renewable Energy Operated by the Alliance for Sustainable Energy, LLC

This report is available at no cost from the National Renewable Energy Laboratory (NREL) at www.nrel.gov/publications.

Contract No. DE-AC36-08GO28308
Conference Paper

NREL/CP-5400-74284

December 2019

National Renewable Energy Laboratory 15013 Denver West Parkway Golden, CO 80401 303-275-3000 • www.nrel.gov 


\section{NOTICE}

This work was authored by the National Renewable Energy Laboratory, operated by Alliance for Sustainable Energy, LLC, for the U.S. Department of Energy (DOE) under Contract No. DE-AC36-08GO28308. Funding was provided by the U.S. Department of Energy Office of Energy Efficiency and Renewable Energy Vehicle Technologies Office Electric Drive Technologies Program. The views expressed herein do not necessarily represent the views of the DOE or the U.S. Government. The U.S. Government retains and the publisher, by accepting the article for publication, acknowledges that the U.S. Government retains a nonexclusive, paid-up, irrevocable, worldwide license to publish or reproduce the published form of this work, or allow others to do so, for U.S. Government purposes.

This report is available at no cost from the National Renewable Energy Laboratory (NREL) at www.nrel.gov/publications.

U.S. Department of Energy (DOE) reports produced after 1991 and a growing number of pre-1991 documents are available free via www.OSTI.gov.

Cover Photos by Dennis Schroeder: (clockwise, left to right) NREL 51934, NREL 45897, NREL 42160, NREL 45891, NREL 48097, NREL 46526.

NREL prints on paper that contains recycled content. 


\section{SURFACE TEMPERATURE EFFECT ON CONVECTIVE HEAT TRANSFER COEFFICIENTS FOR JET IMPINGEMENT COOLING OF ELECTRIC MACHINES WITH AUTOMATIC TRANSMISSION FLUID

\author{
Bidzina Kekelia ${ }^{1}$, Kevin Bennion, Xuhui Feng, Gilberto Moreno, J. Emily Cousineau, Sreekant \\ Narumanchi, Jeff Tomerlin \\ National Renewable Energy Laboratory, Golden, CO, USA
}

\begin{abstract}
In this study, the results of NREL's continued work on experimental characterization of the thermal performance of free-surface jets of automatic transmission fluid impinged on a heated target surface are presented. The measured heat transfer coefficients are useful for understanding factors influencing performance of driveline fluid-based cooling systems for electric machines and help designers in developing high-performance, power-dense and reliable machines. Experiments were carried out for different fluid and target surface temperatures $\left(50^{\circ} \mathrm{C}\right.$, $70^{\circ} \mathrm{C}$, and $90^{\circ} \mathrm{C}$ for the fluid and $90^{\circ} \mathrm{C}, 100^{\circ} \mathrm{C}, 110^{\circ} \mathrm{C}$, and $120^{\circ} \mathrm{C}$ for the target surface). Impinging jet velocities $(0.5 \mathrm{~m} / \mathrm{s}$ to 7.5 $\mathrm{m} / \mathrm{s}$ ) and the jet position on the target surface (center versus edge) were also varied. The impinging angle was kept at $90^{\circ}$ relative to the target surface. It was found that higher target surface temperature increased heat transfer coefficients, namely, increasing surface temperature from $90^{\circ} \mathrm{C}$ to $120^{\circ} \mathrm{C}$ enhanced heat transfer coefficient values at higher impinged jet velocities $(7.5 \mathrm{~m} / \mathrm{s})$ by up to $15 \%$.
\end{abstract}

Keywords: Jet impingement, automatic transmission fluid, electric machines, electric motors, thermal management

$\begin{array}{cl}\text { NOMENCLATURE } \\ A & \text { Target impingement surface area } \\ h & \text { Heat transfer coefficient } \\ k & \text { Thermal conductivity } \\ \mathrm{d}_{1} & \begin{array}{l}\text { Distance between two thermocouples } \\ \text { embedded in the target }\end{array} \\ \mathrm{d}_{2} & \begin{array}{l}\text { Distance from upper thermocouple to target's } \\ \text { top (cooled) surface }\end{array} \\ \mathrm{d}_{\mathrm{o}} & \text { Nozzle orifice diameter } \\ \mathrm{D} & \text { Target impingement surface diameter } \\ Q & \text { Heat dissipated through target's top surface } \\ \mathrm{S} & \text { Distance between nozzle and target surface } \\ T_{\text {fluid }} & \text { Fluid temperature at nozzle inlet } \\ T_{\text {surface }} & \text { Target surface temperature } \\ T_{\text {lower }} & \text { Lower thermocouple temperature }\end{array}$

$$
T_{\text {upper }} \quad \text { Upper thermocouple temperature }
$$

\section{INTRODUCTION}

Thermal management of electric machines (electric motors and generators) is becoming increasingly important as the transition to vehicles with fully electric propulsion systems in the automotive industry picks up pace. With increasing power density of electric traction drives without sacrificing performance or reliability, the challenges associated with thermal management for electric machines increase. Appropriate thermal design is as important as electromagnetic and mechanical design of the electric machine [1]. In addition to optimizing the passive thermal design (geometric layout of components, material selection, thermal interfaces affecting the heat spreading capabilities within the electric machine) for highpower electric motor or generator, it is necessary to actively remove heat from key components of the machine. The convective cooling mechanism transfers heat from those components to an intermediary fluid and ultimately rejects the heat to the ambient environment. Cooling of the electric machine in a vehicle can be accomplished by circulating coolant, such as water-ethylene glycol (WEG), through the stator case or impinging automatic transmission fluid (ATF) jets onto the machine's copper windings. The latter cooling method is advantageous because the windings are typically the most temperature-sensitive component in the machine. Also, because in many cases the electric machines are housed within the vehicle's transmission or transaxle where ATF is readily available, no additional cooling fluid is required. Besides, ATF is a dielectric and can be in direct contact with electrically active machine components.

\section{Direct cooling of end-windings}

A very effective method for removing heat from the electric machine is directly cooling the end-windings of a stator with dielectric fluid impinged on the windings. The winding materials such as insulation are an example of temperature-sensitive components in the machine. In this study, ATF is used and evaluated as a cooling medium. Thermal (heat capacity) and

\footnotetext{
${ }^{1}$ Contact author: bidzina.kekelia@nrel.gov
} 
physical (highly temperature-dependent viscosity) properties of ATF are inferior to those of WEG, which is generally used in water jacket cooling incorporated in the stator casing. However, ATF is readily available within a vehicle's transmission where the electric machine is often housed, making it an attractive single cooling and lubricating fluid option for the electric vehicle traction drive designers and manufacturers. Besides the ability to directly cool and remove heat generated within the windings, direct cooling with ATF avoids the conduction path thermal resistance through the passive stack of other materials present in a water jacket WEG cooling scenario [2].

\section{Oil cooling performance}

Understanding and characterizing heat transfer using oil jets, specifically ATF jet impingement cooling are critical for automotive original equipment manufacturers. There is little publicly available information on this topic. However, some limited data on thermal performance of viscous, high-Prandtlnumber fluids (e.g., oils) and their applications for cooling electric machines, internal combustion engine pistons and transformer windings have been reported in the literature [3-14]. A detailed overview of the literature with relevant experimental and theoretical work is provided in the National Renewable Energy Laboratory's (NREL's) previous publication [15] on this topic.

The current work is a continuation of NREL's efforts for characterization of thermal performance of free-surface jet impingement cooling of electric machines with ATF $[2,15]$. Previous work focused on the influence of target surface topography and physical enhancements on the heat transfer performance, where four different target samples were evaluated [15]. Baseline (flat surface) sample performance was also compared against results obtained from literature correlations and was found to be within the range of those correlations, although clearly diverging from correlation predictions towards the higher flow velocities. During recent experiments, it was found that the target surface temperature significantly affects convective heat transfer coefficients.

\section{EXPERIMENTAL SETUP AND PROCEDURES}

\section{Fluid test loop}

Heat transfer measurements were conducted using a fluid test loop designed for characterization of forced convective thermal performance of fluids. A general view of the experimental setup can be seen in Figure 1.

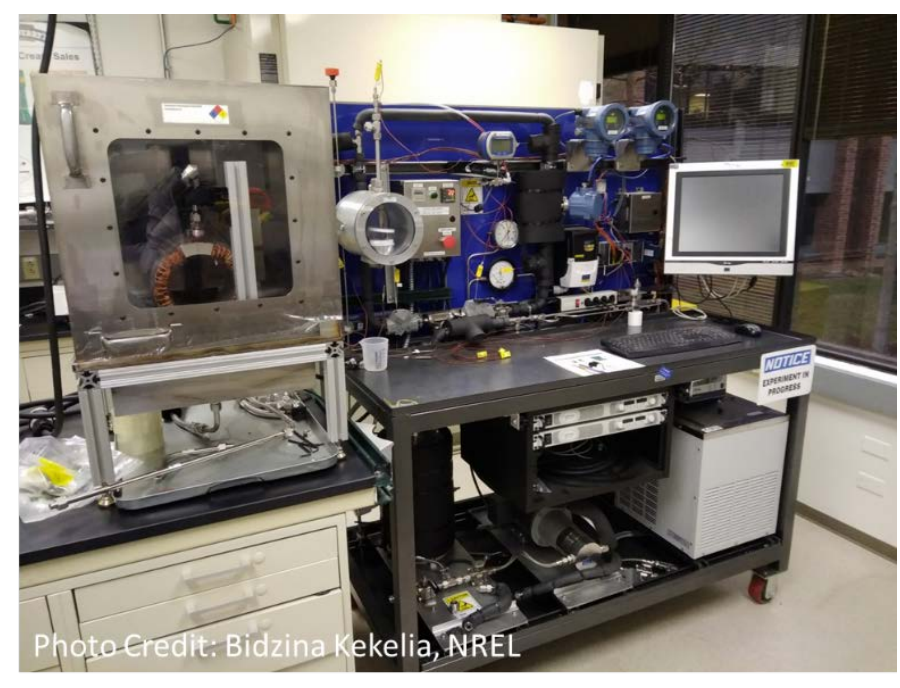

Figure 1. General view of experimental fluid test loop.

The test loop can be configured for jet impingement or channel flow experiments and can accommodate a variety of test articles: from small heated targets to entire electric machines. A schematic of the experimental test loop is provided in Figure 2.

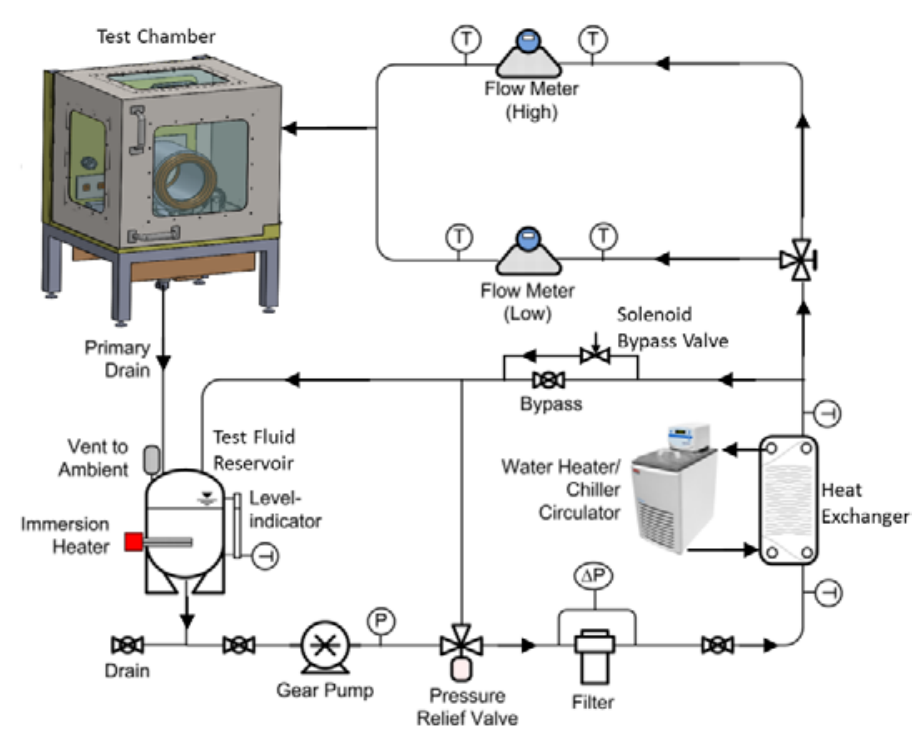

Figure 2. Fluid test loop schematic.

Ford Motor Company's Mercon LV automatic transmission fluid was evaluated in this study because of its use in hybrid electric vehicles. Ford provided thermal and physical properties of the fluid. The fluid is circulated through the loop via a variable-frequency-drive-controlled gear pump. System fluid temperatures are controlled and held constant using a heater/chiller bath circulator and flat-plate heat exchanger system as well as an immersion heater located within the reservoir tank. Two Coriolis mass flow meters $(0-2 \mathrm{lpm}$ and 2 $-20 \mathrm{lpm}$ ) measure fluid-flow rates. Temperatures within the 
loop are measured with calibrated $\left( \pm 0.09^{\circ} \mathrm{C}\right)$ K-type thermocouples.

\section{Jet impingement test section and heated target}

The ATF jet impingement experiments were conducted in a test chamber containing an electric machine with exposed endwindings and heated target assembly (Figure 3a) mounted within a sectional cutout in the end-windings (Figure 4). The electric machine stator is used for holding and positioning (rotating) the heated target assembly under vertically impinging fluid jet.
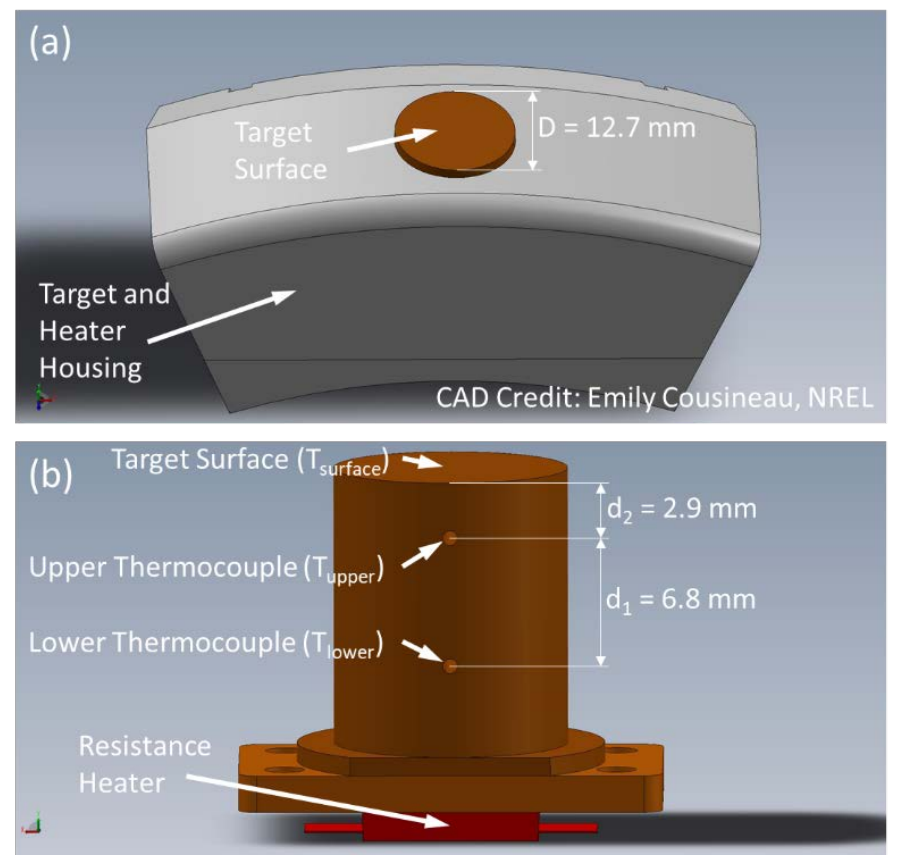

Figure 3. Heated target assembly: (a) assembled housing with exposed target resembling a section of electric machine endwindings, (b) copper target with thermocouple locations and resistance heater mounted on the bottom.

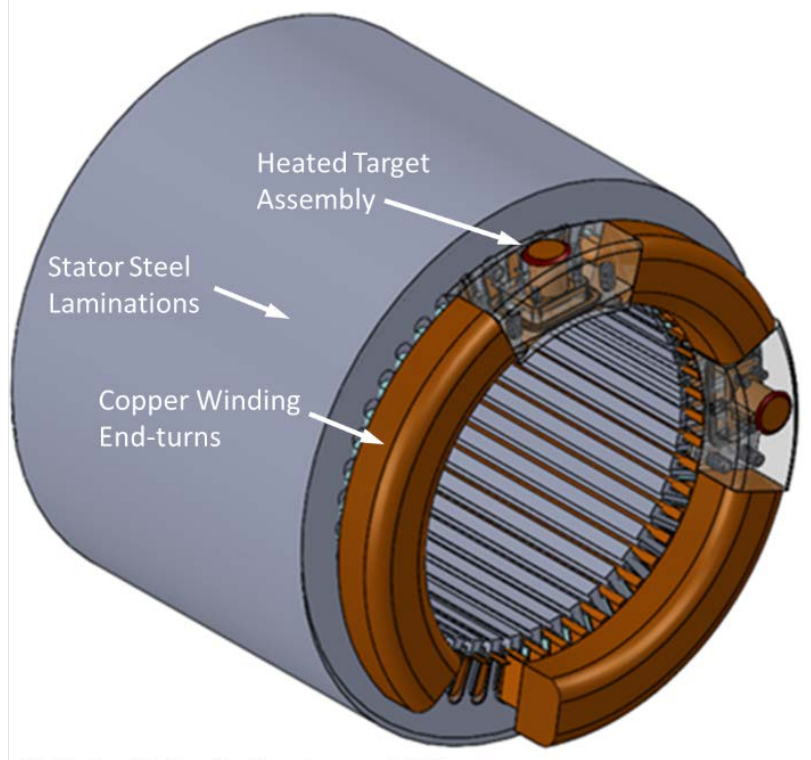

CAD Credit: Emily Cousineau, NREL

Figure 4. Electric machine stator with mounted heated target assembly within the end-windings cutout.

The target was fabricated from oxygen-free copper with a diameter of $\mathrm{D}=12.7 \mathrm{~mm}$ and 600-grit sandpaper-polished impingement (cooled) surface (Figure 3b). A resistance heater was attached to the bottom of the copper target and enclosed in a polyetheretherketone (PEEK) housing for support and thermal insulation. Two calibrated $\left( \pm 0.09^{\circ} \mathrm{C}\right) \mathrm{K}$-type thermocouples were embedded within the target in order to measure heat fluxes from the heater towards the cooled top surface. Copper wires were epoxied on the top surface of the target housing (adjacent to the exposed target surface) to replicate the texture of end windings and directing fluid towards other windings after flowing over the heated target.

An orifice nozzle with $\mathrm{d}_{\mathrm{o}}=2.06 \mathrm{~mm}$ diameter was positioned at $\mathrm{S}=10 \mathrm{~mm}$ distance above the circular target and aimed at a $90^{\circ}$ angle towards the flat target surface. Fluid temperature $\left(T_{\text {fluid }}\right)$ was measured with a calibrated $\left( \pm 0.09^{\circ} \mathrm{C}\right)$ K-type thermocouple installed at the inlet of the nozzle. Figure 5 shows the test section with ATF jet impinging on the heated target. A pressure drop across the nozzle was not recorded as the data for the same orifice nozzle and the same ATF flow rates (velocities) was already reported in NREL's previous publication [15]. 


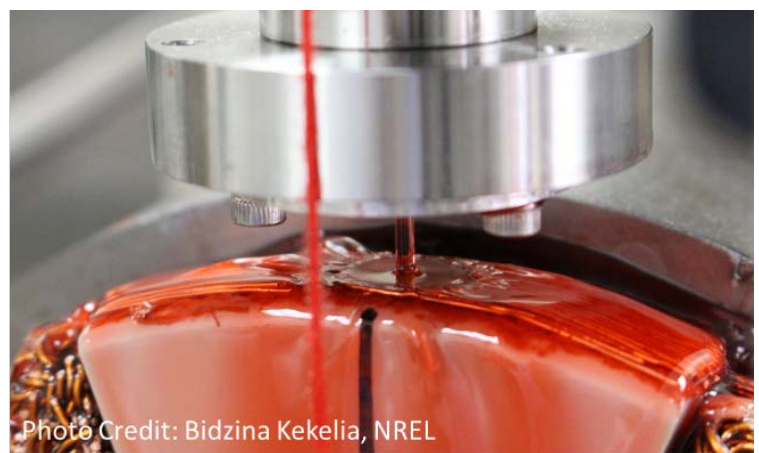

Figure 5. ATF jet impinging on a heated target surface.

\section{Experimental procedures}

The experiments were conducted at $50^{\circ} \mathrm{C}, 70^{\circ} \mathrm{C}$, and $90^{\circ} \mathrm{C}$ fluid temperatures (as measured at the inlet of the nozzle). The test fluid was pre-heated with a direct immersion heater and then the desired fluid temperature was maintained with a silicon bath water heater/chiller through a flat heat exchanger (see Figure 2). The flow rate was controlled by adjusting manual and solenoid bypass valves. The target surface temperature for each experiment was set sequentially at $90^{\circ} \mathrm{C}, 100^{\circ} \mathrm{C}, 110^{\circ} \mathrm{C}$, and $120^{\circ} \mathrm{C}$. The surface temperatures were achieved by controlling a direct-current power supply connected to the resistance heater on the bottom of the heated target. The experiments were monitored and controlled with a LabVIEW program via National Instrument's CompactDAQ data acquisition system.

After reaching steady temperature and flow conditions, data were recorded (45 data points at 2-sec intervals) for each test case and repeated a minimum of three times. The heat transfer coefficient values were calculated for each data point and recorded by the LabVIEW control program. Average heat transfer coefficients $(\bar{h})$ for the target surface were defined according to Equation 1:

$$
\bar{h}=\frac{Q}{A\left(T_{\text {surface }}-T_{\text {fluid }}\right)}
$$

where $Q$ is the heat dissipated through the top surface (with surface area of $A$ ) of the target, $T_{\text {surface }}$ is the target's average impingement surface temperature and $T_{\text {fluid }}$ is the fluid temperature at the inlet of the nozzle. Due to the highly conductive properties $(k)$ of the oxygen-free copper target and the low conductivity of the PEEK housing, one-dimensional heat transfer can be assumed within the cylindrical body of the target. During steady-state conditions, variations in temperature in cross-sectional planes of the target would be relatively insignificant with $T_{\text {surface, }}, T_{\text {upper }}$ and $T_{\text {lower }}$ representing average temperatures in respective cross-sectional planes (see Figure $3 b$ for reference). Considering the assumptions mentioned above and neglecting losses to the sides, heat flow from the bottom of the target towards the top surface can be calculated as in Equations 2 and 3 below:

$$
\begin{aligned}
& Q=-k A \frac{T_{\text {upper }}-T_{\text {lower }}}{d_{1}} \\
& Q=-k A \frac{T_{\text {surface }}-T_{\text {upper }}}{d_{2}}
\end{aligned}
$$

As Equation 3 is equal to Equation 2, the target surface temperature can be calculated as shown in Equation 4.

$$
T_{\text {surface }}=T_{\text {upper }}+\frac{d_{2}\left(T_{\text {upper }}-T_{\text {lower }}\right)}{d_{1}}
$$

Finally, after substitutions, Equation 1 for the heat transfer coefficients could be expressed as Equation 5, where all terms are either known or measured during the experiments:

$$
\bar{h}=k \frac{T_{\text {lower }}-T_{\text {upper }}}{d_{1}\left(T_{\text {upper }}-T_{\text {fluid }}\right)-d_{2}\left(T_{\text {lower }}-T_{\text {upper }}\right)}
$$

\section{RESULTS AND DISCUSSION}

In order to quantify the target surface temperature effect on ATF jet impingement convective heat transfer coefficients, a series of experiments were performed. The matrix of key parameters varied during the experiments is presented in Table 1.

Table 1. Parameters varied during the experiments.

\begin{tabular}{|l|l|}
\hline \multicolumn{1}{|c|}{ Parameter } & \multicolumn{1}{c|}{ Values } \\
\hline Fluid temperature $\left(T_{\text {fluid }}\right)$ & $50^{\circ} \mathrm{C}, 70^{\circ} \mathrm{C}, 90^{\circ} \mathrm{C}$ \\
\hline Fluid flow rate (average jet velocity) & $0.1 \mathrm{Ipm}(0.5 \mathrm{~m} / \mathrm{s})^{*}$ \\
& $0.15 \mathrm{Ipm}(0.75 \mathrm{~m} / \mathrm{s})^{* *}$ \\
& $0.25 \mathrm{Ipm}(1.25 \mathrm{~m} / \mathrm{s})$ \\
& $0.5 \mathrm{Ipm}(2.5 \mathrm{~m} / \mathrm{s})$ \\
& $1.0 \mathrm{Ipm}(5.0 \mathrm{~m} / \mathrm{s})$ \\
& $1.5 \mathrm{Ipm}(7.5 \mathrm{~m} / \mathrm{s})$ \\
\hline Target surface temperature $\left(T_{\text {surface }}\right)$ & $90^{\circ} \mathrm{C}^{*}, 100^{\circ} \mathrm{C}, 110^{\circ} \mathrm{C}, 120^{\circ} \mathrm{C}$ \\
\hline Jet incidence location on target surface & center, edge \\
\hline *Only for experiments with $50^{\circ} \mathrm{C}$ and $70^{\circ} \mathrm{C}$ fluid temperatures. \\
**Only for experiments with $90^{\circ} \mathrm{C}$ fluid temperature.
\end{tabular}

Despite insulation, a significant amount of heat was lost to the ambient environment from the experimental fluid loop bench. This was especially evident at higher fluid temperatures and low flow rates (low heat carrying capability). As the fluid path from the heat exchanger to the nozzle inlet was over 4 meters, at the lowest flow rates $(0.1-0.15 \mathrm{lpm})$ the heated fluid cooled down by more than $20^{\circ}-25^{\circ} \mathrm{C}$ before reaching the nozzle inlet. Maintaining a $90^{\circ} \mathrm{C}$ nozzle inlet temperature required elevating fluid temperatures in the reservoir and at the outlet of the heat exchanger up to $115^{\circ}-120^{\circ} \mathrm{C}$ (with even higher heater temperature settings), approaching safety and operational limits 
of the setup. This prevented us from performing $90^{\circ} \mathrm{C}$ fluid temperature experiments below $0.15 \mathrm{lpm}$ flow rate.

The results of the experiments are shown in Figure 6, Figure 7, and Figure 8, where the average heat transfer coefficients are plotted against average jet velocities for $50^{\circ} \mathrm{C}, 70^{\circ} \mathrm{C}$ and $90^{\circ} \mathrm{C}$ fluid temperatures. The experiments were performed for the jet impinging in the center and at the edge of a round target surface.

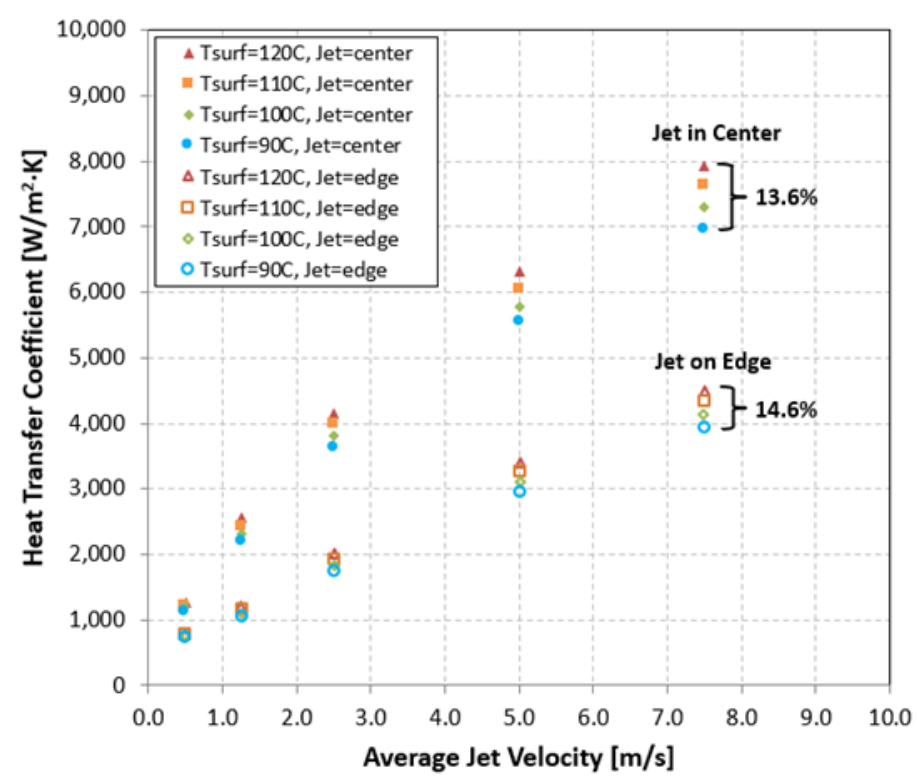

Figure 6. Heat transfer coefficients for $50^{\circ} \mathrm{C}$ fluid temperature.

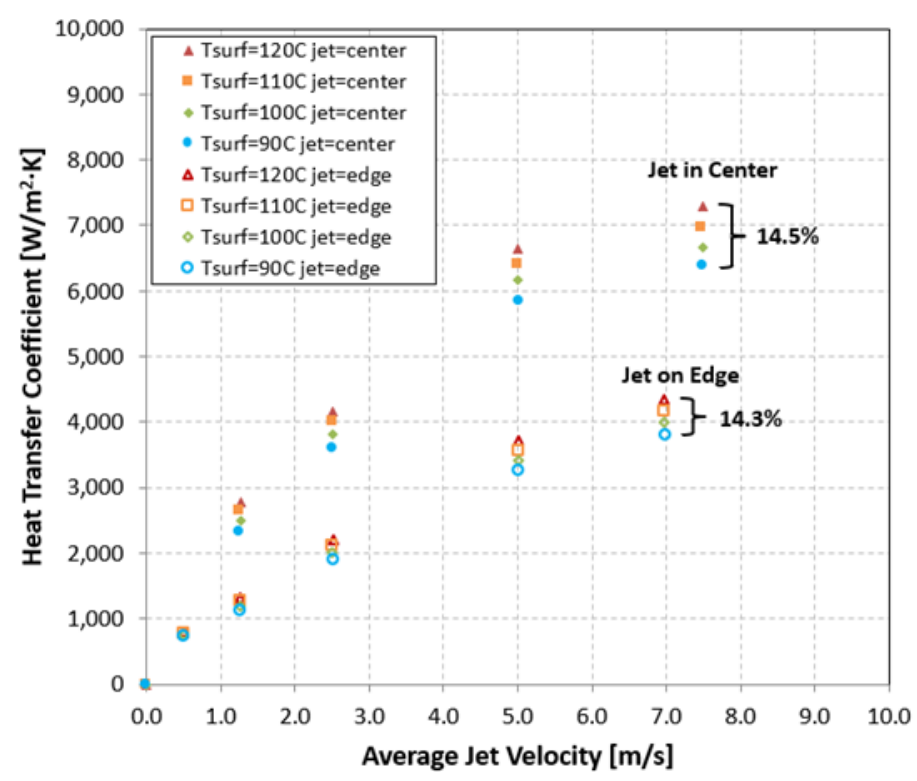

Figure 7. Heat transfer coefficients for $70^{\circ} \mathrm{C}$ fluid temperature.

As expected, the heat transfer coefficients increased with increasing impinging jet velocity. The heat transfer coefficients are higher for jets impinging in the center of the target compared to those impinging on the edge. This is also expected, as in the latter case only a fraction of impinged fluid flows over the target surface, decreasing its cooling effect. As in NREL's previous studies [15], the current experimental results showed negligible, if any, influence of fluid temperature (measured at the nozzle inlet) on heat transfer coefficients.

From Figure 6 and Figure 7, it can be seen that at the highest tested velocities $(7.0-7.5 \mathrm{~m} / \mathrm{s})$, a target surface temperature variation from $90^{\circ} \mathrm{C}$ to $120^{\circ} \mathrm{C}$ yielded $13 \%-15 \%$ variation in heat transfer coefficient values. For the $90^{\circ} \mathrm{C}$ fluid temperature (Figure 8) case, the heat transfer coefficient variation is smaller, within $11 \%-12 \%$, which is due to a narrower range of target surface temperatures tested $\left(100^{\circ} \mathrm{C}\right.$ to $\left.120^{\circ} \mathrm{C}\right)$. At lower flow velocities, the surface temperature impact on the heat transfer coefficient values decreases although it is still clearly distinguishable. The observed heat transfer enhancement phenomenon is likely due to increased ATF film temperature near the heated surface, resulting in reduced viscosity (strongly temperature-dependent property for ATF), in turn increasing fluid flow and heat transfer in the vicinity of the surface.

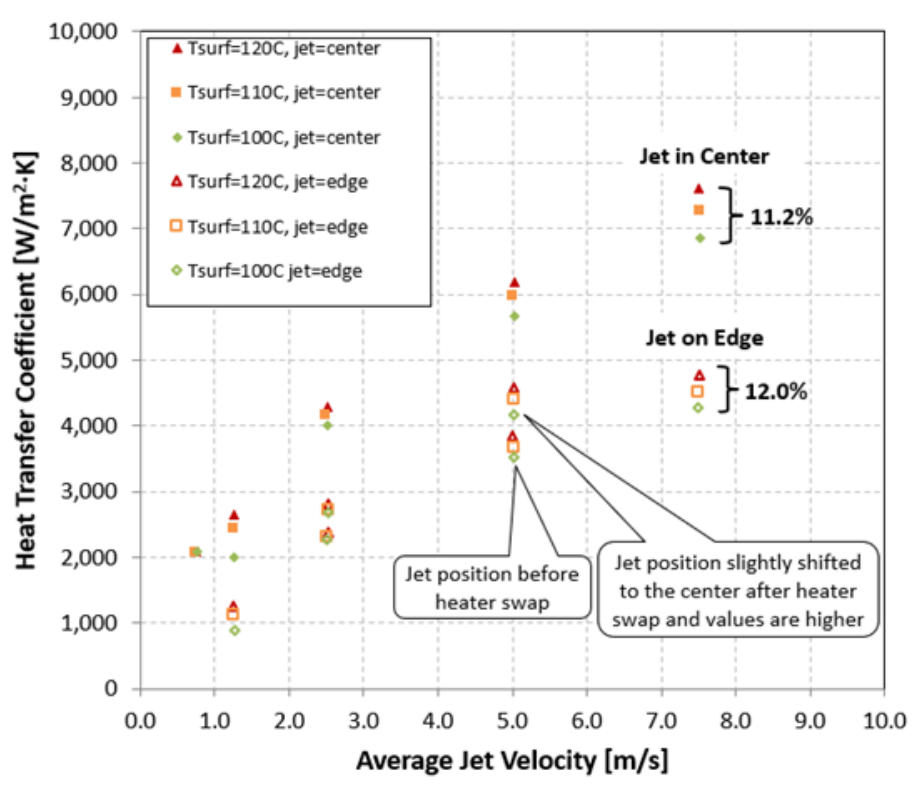

Figure 8. Heat transfer coefficients for $90^{\circ} \mathrm{C}$ fluid temperature.

In Figure 8, two sets of data for target edge jet impingement at $2.5 \mathrm{~m} / \mathrm{s}$ and $5.0 \mathrm{~m} / \mathrm{s}$ flow velocities can be seen. This illustrates the sensitivity of the jet incidence location alignment with the edge of the target. After replacing a burnt heater in the target assembly, the position of the impinged jet on target surface had slightly shifted towards the center $(\approx 1 \mathrm{~mm})$, resulting in a larger fraction of fluid flowing over the target surface versus away from the surface. A similar small alignment mismatch for target center jet impingement would not have had a noticeable effect (as all impinged fluid still would have flowed over the target surface), whereas in the case of the target edge impingement, it noticeably increased the heat transfer. Namely, the larger amount of fluid carrying away more heat increased measured heat transfer coefficient values. To prevent future errors in edge impingement 
experiments, a more accurate jet-to-target alignment mechanism design is planned.

The uncertainties for key data points are reported in Table 2 and Table 3. In Table 2 uncertainties in average jet velocities for the lowest and highest velocities (flow rates) are reported. In Table 3 the uncertainties in heat transfer coefficients for lowest and highest jet speeds (flow rates) and surface temperatures (for target center impingement experiments) are provided.

Table 2. Uncertainties in average jet velocities.

\begin{tabular}{|l|c|c|c|}
\hline Uncertainties in Average Jet Velocity & $\begin{array}{c}0.5 \mathrm{~m} / \mathrm{s} \\
(0.1 \mathrm{Ipm})\end{array}$ & $\begin{array}{c}0.75 \mathrm{~m} / \mathrm{s} \\
(0.15 \mathrm{Ipm})\end{array}$ & $\begin{array}{c}7.5 \mathrm{~m} / \mathrm{s} \\
(1.5 \mathrm{Ipm})\end{array}$ \\
\hline $\mathrm{U}_{95}$ at $\mathrm{T}_{\text {fluid }}=50^{\circ} \mathrm{C}$ & $\pm 1.8 \%$ & $\mathrm{~N} / \mathrm{A}$ & $\pm 1.0 \%$ \\
\hline $\mathrm{U}_{95}$ at $\mathrm{T}_{\text {fluid }}=70^{\circ} \mathrm{C}$ & $\pm 1.3 \%$ & $\mathrm{~N} / \mathrm{A}$ & $\pm 1.0 \%$ \\
\hline $\mathrm{U}_{95}$ at $\mathrm{T}_{\text {fluid }}=90^{\circ} \mathrm{C}$ & $\mathrm{N} / \mathrm{A}$ & $\pm 1.2 \%$ & $\pm 1.0 \%$ \\
\hline
\end{tabular}

Table 3. Uncertainties in heat transfer coefficients for highest and lowest jet velocities and target surface temperatures.

\begin{tabular}{|c|c|c|c|c|}
\hline $\begin{array}{l}\text { Uncertainties in Heat Transfer } \\
\quad \text { Coefficient } \\
\text { (target center impingement) }\end{array}$ & $\begin{array}{c}0.5 \mathrm{~m} / \mathrm{s} \\
(0.1 \mathrm{lpm})\end{array}$ & $\begin{array}{l}0.75 \mathrm{~m} / \mathrm{s} \\
(0.15 \mathrm{lpm})\end{array}$ & $\begin{array}{c}1.25 \mathrm{~m} / \mathrm{s} \\
(0.25 \mathrm{Ipm})\end{array}$ & $\begin{array}{c}7.5 \mathrm{~m} / \mathrm{s} \\
(1.5 \mathrm{lpm})\end{array}$ \\
\hline $\mathrm{U}_{95}$ at $\mathrm{T}_{\text {fluid }}=50^{\circ} \mathrm{C}$ and $\mathrm{T}_{\text {surface }}=90^{\circ} \mathrm{C}$ & $\pm 16.7 \%$ & N/A & $\pm 8.8 \%$ & $\pm 3.0 \%$ \\
\hline $\mathrm{U}_{95}$ at $\mathrm{T}_{\text {fluid }}=50^{\circ} \mathrm{C}$ and $\mathrm{T}_{\text {surface }}=120^{\circ} \mathrm{C}$ & $\pm 8.6 \%$ & N/A & $\pm 4.4 \%$ & $\pm 1.6 \%$ \\
\hline $\mathrm{U}_{95}$ at $\mathrm{T}_{\text {fluid }}=70^{\circ} \mathrm{C}$ and $\mathrm{T}_{\text {surface }}=90^{\circ} \mathrm{C}$ & N/A & N/A & $\pm 16.4 \%$ & $\pm 6.4 \%$ \\
\hline $\mathrm{U}_{95}$ at $\mathrm{T}_{\text {fluid }}=70^{\circ} \mathrm{C}$ and $\mathrm{T}_{\text {surface }}=120^{\circ} \mathrm{C}$ & N/A & N/A & $\pm 5.5 \%$ & $\pm 3.25 \%$ \\
\hline $\mathrm{U}_{95}$ at $\mathrm{T}_{\text {fluid }}=90^{\circ} \mathrm{C}$ and $\mathrm{T}_{\text {surface }}=100^{\circ} \mathrm{C}$ & N/A & $\pm 37.4 \%$ & $\pm 37.1 \%$ & $\pm 11.8 \%$ \\
\hline $\mathrm{U}_{95}$ at $\mathrm{T}_{\text {fluid }}=90^{\circ} \mathrm{C}$ and $\mathrm{T}_{\text {surface }}=120^{\circ} \mathrm{C}$ & N/A & $\pm 12.2 \%$ & $\pm 9.8 \%$ & $\pm 3.7 \%$ \\
\hline
\end{tabular}

As it can be seen from Table 3, the highest uncertainties are at low jet velocities (flow rates) with the lowest target surface temperatures. During these experiments, upward heat flux through the target body is relatively low, resulting in small temperature difference (less than $1^{\circ} \mathrm{C}$ ) between the lower and upper thermocouples (see Figure $3 b$ ), which in turn yields relatively high uncertainty in the respective heat transfer coefficient calculations. The lowest uncertainties at high jet velocities (flow rates) with the highest target surface temperatures reflect higher heat fluxes, thus, higher temperature differences between the lower and upper thermocouples, hence, smaller relative errors. The reported lower uncertainties can also be attributed to the fact that most experimental runs were performed back to back with several minutes apart and with little variation in experimental conditions, resulting in closely matched values of calculated heat transfer coefficients.

\section{CONCLUSIONS}

This paper provides experimental data on free-jet impingement convective heat transfer coefficients applicable for end-winding cooling of electric machines with ATF present in the traction drives of electric and hybrid vehicles. The data are expected to be directly useful to researchers and motor manufacturers in the design and development of power-dense, high-performance electric machines. It was found that the target surface temperature has a significant effect on jet impingement cooling with ATF. The impact was quantified for jet velocities from $0.5 \mathrm{~m} / \mathrm{s}$ to $7.5 \mathrm{~m} / \mathrm{s}$, and the results showed that increasing target surface temperature from $90^{\circ} \mathrm{C}$ to $120^{\circ} \mathrm{C}$ enhanced heat transfer coefficient values at higher impingement jet velocities $(7.5 \mathrm{~m} / \mathrm{s})$ by up to $15 \%$. The observed heat transfer enhancement phenomenon is likely due to increased ATF film temperature near the heated surface, resulting in reduced viscosity (a strongly temperature-dependent property for ATF) and consequently, increased fluid flow and heat transfer in the vicinity of the surface.

\section{ACKNOWLEDGMENTS}

The authors would like to acknowledge the support provided by Susan Rogers, Technology Manager of the Electric Drive Technologies Program, Vehicle Technologies Office, U.S. Department of Energy Office of Energy Efficiency and Renewable Energy.

This work was authored by the National Renewable Energy Laboratory, operated by the Alliance for Sustainable Energy, LLC, for the U.S. Department of Energy (DOE) under Contract No. DE-AC36-08GO28308. Funding was provided by the DOE Vehicle Technologies Office Electric Drive Technologies Program. The views expressed in the article do not necessarily represent the views of the DOE or the U.S. Government. The U.S. Government retains and the publisher, by accepting the article for publication, acknowledges that the U.S. Government retains a nonexclusive, paid-up, irrevocable, worldwide license to publish or reproduce the published form of this work, or allow others to do so, for U.S. Government purposes.

\section{REFERENCES}

[1] Hendershot, J. R., and Miller, T. J. E., 1994, Design of brushless permanent-magnet motors, Magna Physics Pub., Oxford, UK.

[2] Bennion, K., and Cousineau, J., 2012, "Sensitivity analysis of traction drive motor cooling," IEEE Transportation Electrification Conference and Expo (ITEC), pp. 1-6.

[3] Brooke, A. L., 2011, Chevrolet Volt: Development story of the pioneering electrified vehicle, SAE International.

[4] Burress, T., Coomer, C., Campbell, S., Wereszczak, A., Cunningham, J., Marlino, L., Seiber, L., and Lin, H.-T., 2009, Evaluation of the 2008 Lexus LS $600 H$ hybrid synergy drive system, ORNL/TM-2008/185, Oak Ridge National Laboratory, Oak Ridge, TN.

[5] Davin, T., Pellé, J., Harmand, S., and Yu, R., 2015, "Experimental study of oil cooling systems for electric motors," Appl. Therm. Eng., 75, pp. 1-13.

[6] Lim, D. H., and Kim, S. C., 2014, "Thermal performance of oil spray cooling system for in-wheel motor in electric vehicles," Appl. Therm. Eng., 63(2), pp. 577-587.

[7] Easter, J., Jarrett, C., Pespisa, C., Liu, Y. C., Alkidas, A. C., Guessous, L., and Sangeorzan, B. P., 2014, “An area-average correlation for oil-jet cooling of 
automotive pistons," J. Heat Transf., 136(12), pp. 124501-124501-4.

[8] Liu, Y., Guessous, L., Sangeorzan, B., and Alkidas, A., 2014, "Laboratory Experiments on Oil-Jet Cooling of Internal Combustion engine pistons: area-average correlation of oil-jet impingement heat transfer," $J$. Energy Eng., p. C4014003.

[9] Metzger, D. E., Cummings, K. N., and Ruby, W. A., 1974, "Effects of Prandtl number on heat transfer characteristics of impinging liquid jets.," Int. Heat Transf. Conf 5th Proc, Tokyo, Japan, pp. 20-24.

[10]Leland, J. E., and Pais, M. R., 1999, "Free jet impingement heat transfer of a high Prandtl number fluid under conditions of highly varying properties," $J$. Heat Transf., 121(3), pp. 592-597.

[11]Sun, H., Ma, C. F., and Chen, Y. C., 1998, "Prandtl number dependence of impingement heat transfer with circular free-surface liquid jets," Int. J. Heat Mass Transf., 41(10), pp. 1360-1363.

[12] Ma, C. F., Zheng, Q., and Ko, S. Y., 1997, “Local heat transfer and recovery factor with impinging freesurface circular jets of transformer oil," Int. J. Heat Mass Transf., 40(18), pp. 4295-4308.

[13] Ma, C. F., Zheng, Q., Lee, S. C., and Gomi, T., 1997, "Impingement heat transfer and recovery effect with submerged jets of large Prandtl number liquid-I. unconfined circular jets," Int. J. Heat Mass Transf., 40(6), pp. 1481-1490.

[14] Ma, C. F., Sun, H., Auracher, H., and Gomi, T., 1990, "Local convective heat transfer from vertical heated surfaces to impinging circular jets of large Prandtl number liquid," Proceedings of the Ninth International Heat Transfer Conference, Jerusalem, Israel, pp. 441446.

[15]Bennion, K., and Moreno, G., 2015. "Convective heat transfer coefficients of automatic transmission fluid jets with implications for electric machine thermal management," ASME 2015 International Technical Conference and Exhibition on Packaging and Integration of Electronic and Photonic Microsystems, San Francisco, CA, United States. Vol 3. doi:10.1115/IPACK2015-48382. 